\title{
EFFECT OF BIPHASIC BONE GRAFT MATERIAL (BGM) IN COMBINATION WITH AUTOLOGOUS PLATELET-RICH FIBRIN (PRF) ON BONE REGENERATION IN AN ODONTOGENIC MAXILLARY CYST: A RANDOMIZED CONTROLLED CLINICAL TRIAL
}

\author{
Sherif A. Moneem*, Heba M. Kamel ${ }^{* *}$ and Niveen A. Asker ${ }^{* * *}$
}

\begin{abstract}
Objectives: The purpose of this study was to assess the effect of SYMBIOS® biphasic bone graft material (BGM) in combination with autologous platelets rich fibrin (PRF) on the bone regeneration in the treatment of odontogenic maxillary cysts.

Materials and methods: A total of twenty eight patients suffering from large maxillary odontogenic cysts were treated by enucleation and were randomly assigned into two groups. Each group was formed of fourteen patients. The bony defects were grafted by a combination of SYMBIOS ${ }^{\circledR}$ and PRF in group (A) and application of SYMBIOS ${ }^{\circledR}$ alone in group (B). Post-operative clinical and radiographic follow-up were performed. Pain and swelling scores were measured using VAS at 6 weeks postoperative follow up, while bone density of the bony defects were measured using cone beam computerized tomography (CBCT) at 9 months post-operative follow up.
\end{abstract}

Results: Accelerated wound healing was observed in all cases without any signs of postoperative complications. On the 9th month post-operatively the bone density was increased by $45.03 \%$ in group (A) where is the results of group B.

Conclusion: $S Y M B I O S ® / P R F$ combination accelerated bone healing and improved the quality and quantity of regenerated bone rather than SYMBIOS® ${ }^{\circ}$ alone.

KEYWORDS: Cyst, Bone substitute, PRF, Bone regeneration, SYMBIOS®.

\footnotetext{
* Master Degree of Oral and Maxillofacial Surgery, Faculty of Dentistry, Cairo University.

** Lecturer of Oral and Maxillofacial Surgery, Faculty of Dentistry, Cairo University.

*** Professor of Oral and Maxillofacial Surgery, Faculty of Dentistry, Cairo University.
} 


\section{INTRODUCTION}

Odontogenic cysts are considered one of the most common forms of the cystic lesions that affect the oral and maxillofacial field. Maxillary odontogenic are common in the in the maxillofacial region. ${ }^{11}$ They are considered the main cause of pathological jaw fracture. Their origin, development, growth mechanism and treatment techniques have a great concern of study in the maxillofacial surgery field due to their medical, surgical and esthetical considerations. ${ }^{(2,3)}$

The maxillofacial surgeons are dealing with a massive challenge in the process of treatment of large cysts. Bony defects or cavities have variable sizes arising after the enucleation process of the cystic lesions. The main objective of the treatment process of the cystic lesions is the complete recovery of the anatomical and functional factors of the damaged bony tissues, so there is a great interest in using bone graft materials to restore both anatomical and functional requirements after complete removal of the cystic lesion. ${ }^{(4)}$

Many complications appear in cases with large bony cavities after cystic enculasion such as the presence of defective bone-like tissues which do not fulfill clinical and histological criteria. In addition to high risk of suppuration that may occur due to infection of a hematoma in the defective bony cavity with communication with the intra-oral bacterial flora. The suppuration is a serious post-operative complication, as there is a possibility of spread of infection to the vital spaces in the head and neck region. ${ }^{(5,6)}$

There are multiple factors that are mandatory in the treatment plan of a large maxillary odontogenic cyst. Those factors affect the healing mechanism such as the defect size, presence of non-vital teeth and the proximity of the lesion to the nasal and the sinus cavities that are considered a great source of infection in the bony cavities post-operatively. These factors have the ability to decrease the regeneration power of the maxillary bone. ${ }^{(7)}$
Platelet rich fibrin (PRF) is a second generation platelet concentrate derived from a natural and progressive polymerization occurring during centrifugation. PRF is rich with growth factors that are very helpful in healing of soft tissues and in bone regeneration. ${ }^{(8)} \mathrm{PRF}$ has the advantage of being applied in the surgical site as a membrane, or fragments mixed with another grafting biomaterials acting as a bio-connector between the grafting biomaterials and the surgical site to capture and activate the stem cells and to help the migration of the osteo-progenitor cells to accumulate in the center of the grafting biomaterials. Also, PRF has the advantage of its low cost and its simple technique. ${ }^{(9)}$

Bone grafts are commonly used in the maxillofacial surgery to promote the formation of bone and enhance the regeneration of tissues. The main function of the bone grafting materials is to act as structural scaffolds and matrices for the promotion of attachment, proliferation and anchorage of osteoblast cells. Multiple classification approaches have been used to organize bone grafting substitutes according to their source, chemical composition and physical properties. ${ }^{(9)}$

Biphasic Bone Graft Material (BGM) is the bone graft material used in this research. It is a resorbable inorganic bone forming material in granular composition of plant origin derived from red marine algae. BGM has many advantages such as: osteoconductive properties, volume stability, and straightforward application. It is available in two grain sizes the first is $(0.2 \mathrm{~mm}$ to $1.0 \mathrm{~mm})$ for the augmentation of small defects and the other is (1.0 $\mathrm{mm}$ to $2.0 \mathrm{~mm}$ ) for the augmentation of large defects and sinus floor elevation. The chemical composition of this interconnected porous biological product has the similarity with the inorganic part forming the bone of the human. ${ }^{(10)}$

Thus, the aim of our study was to assess the effect of SYMBIOS ${ }^{\circledR}$ biphasic bone graft material (BGM) in combination with autologous platelets rich fibrin (PRF) on the bone regeneration in the treatment of odontogenic maxillary cysts. 


\section{MATERIALS AND METHODS}

Twenty eight patients with large maxillary cystic lesions were selected from the outpatient clinic of the Oral and Maxillofacial Surgery Department, Faculty of Dentistry, Cairo University.

\section{Eligibility criteria}

The patients were selected according to the following criteria:

\section{Inclusion criteria:}

1. Age range was 15: 60 years old.

2. A maxillary cyst larger than $3 \mathrm{~cm}$ in size in any dimensions.

3. What about the general health of patient (ASA classification)

\section{Exclusion criteria:}

1. A maxillary cyst smaller than $3 \mathrm{~cm}$ in size. Deleted

2. A mandibular cyst. deleted

3. Patients with thrombotic risk factors or taking anticoagulants drugs.

4. Patients with systemic diseases that may affect the bone healing process.

\section{Study design:}

This study is a randomized clinical trial. Patients were randomly assigned into two equal groups: group (A) and group (B) according to the website (http//www.random.org.eg). Each group was formed of fourteen patients:

\section{$\operatorname{Group}(A)$ :}

Patients had undergone complete removal of the cystic lesion with the application of SYMBIOS $® *$ biphasic bone graft material (BGM) Manufactured by AlgOss Biotechnologies GmbH DENTSPLY. in combination with PRF in the cystic cavity.

\section{$\operatorname{Group}(B)$ :}

Patients had undergone complete removal of the cystic lesion with the application of SYMBIOS $₫$ biphasic bone graft material (BGM) without the application of PRF in the cystic cavity.

\section{Preoperative preparation:}

As regarding the medical history, all patients were free from any systemic diseases. A panoramic radiograph was performed to assess the cystic extension, the teeth involved and the relation to the anatomical landmarks. Endodontic treatment of savable non-vital teeth was performed preoperatively. The cystic fluid was aspirated preoperatively, then the aspirated fluid was sent for histopathological examination.

For preparation of PRF, $20 \mathrm{ml}$ of venous blood was drawn with a plastic syringe. The blood was immediately collected in two $10 \mathrm{ml}$ dry plain glass test tubes. The tubes were immediately centrifuged at $3000 \mathrm{rpm}$ for 12 minutes. After centrifugation, three layers were formed: Red blood cells base layer, a cellular plasma (PPP) top layer, PRF clot in the middle. The PRF clots were removed from the two tubes and the attached red blood cells layer was scraped off and discarded (Fig. 1).

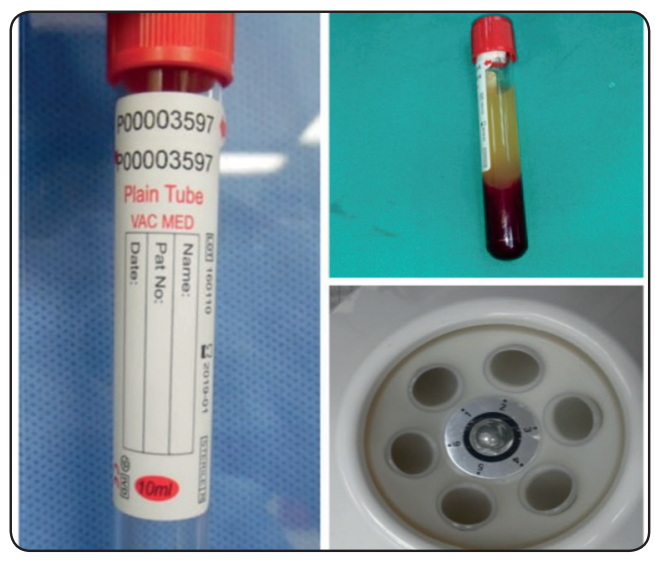

Fig. (1) A Clinical photograph showing the PRF. 


\section{Surgical Procedure:}

All patients were treated under general anaesthesia no local anesthetic was given to the patient as hemostasis ??. A full thickness mucoperiosteal flap was reflected. Careful removal of the bone covering the lesion was made followed by careful enucleation of the cyst. Extraction of non-savable teeth were performed at the same time. The cystic lining was sent for histopathological investigation. In group $(A)$ the grafting material was mixed with the PRF to fill the cystic cavity, while in group $(B)$ the grafting material was applied to fill the cystic cavity. Finally, the mucoperiosteal flap was repositioned and sutured in place (Fig. 2 and 3).

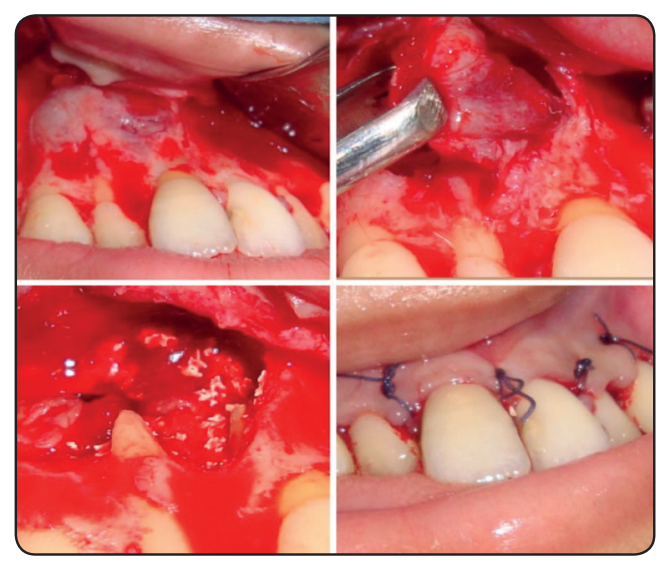

Fig. (2) Clinical photograph showing the surgical technique used for cystic enucleation.

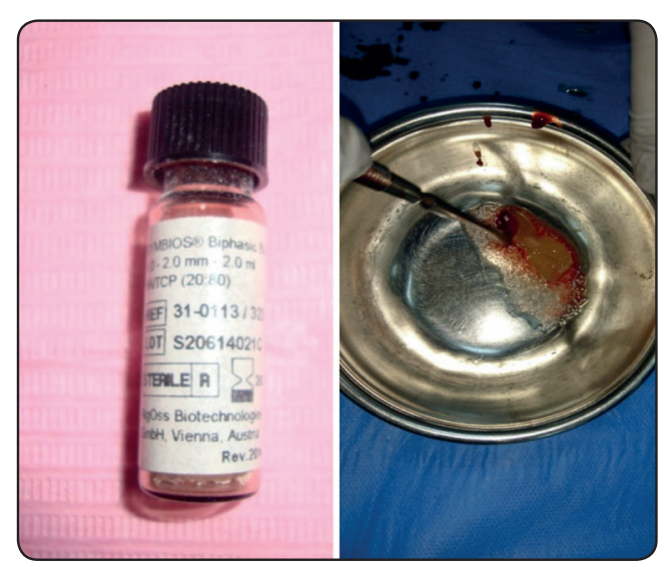

Fig. (3) Aclinical photograph showing mixing of the grafting material.
The patients were recalled for follow up one week post-operatively to evaluate the wound healing and remove the sutures, after 6 weeks to determine the pain and swelling via visual analogue scale (VAS) and 6 months post-operatively then monthly for the remaining 3 months of the follow up period to assess potential post-operative complications. Cone beam computed tomography (CBCT) was performed 9 months post-operatively to measure the bone density.

\section{RESULTS}

This study was conducted on twenty eight patients with large maxillary cystic lesions more than $3 \mathrm{~cm}$ in any dimensions. The age range of the patients was from 15 to 60 years old. The mean age was 33.9 \pm 11.6 in group (A), and $40.4 \pm 8.1$ in group (B), with equal distribution between males and females.

\section{Intraoperative and postoperative complications:}

Minimal amount of bleeding was noticed intra and postoperatively. Proper wound healing was noticed without wound dehiscence in the two groups. Postoperative swelling and pain were manageable. Postoperative infection was absent. No perforation of the maxillary sinus membrane nor injury to the nasal cavity were detected.

\section{Pain and swelling scores}

For both scores, there was no statistically significant difference between the two groups either in the base line or after 6 weeks from the surgery.

\section{Bone density:}

Group (A) showed statistically significantly higher mean bone density than Group (B) ( $P$-value $<0.001$, Effect size $=1.524$ ) at 9 months of follow up. On the 9th month post-operatively the bone density was increased by $45.03 \%$ in group (A) (Table 1). 
TABLE (1): Mean, standard deviation (SD) values and results of Student's t-test for comparison between bone densities in the two groups.

\begin{tabular}{|c|c|c|c|}
\hline $\begin{array}{c}\text { Group (A) } \\
(\mathrm{n}=14)\end{array}$ & $\begin{array}{c}\text { Group (B) } \\
(\mathrm{n}=14)\end{array}$ & P-value & $\begin{array}{c}\text { Effect size } \\
(\mathrm{d})\end{array}$ \\
\hline $574.4(97.1)$ & $404.2(124.6)$ & $<0.001 *$ & 1.524 \\
\hline
\end{tabular}

*: Significant at $P \leq 0.05$

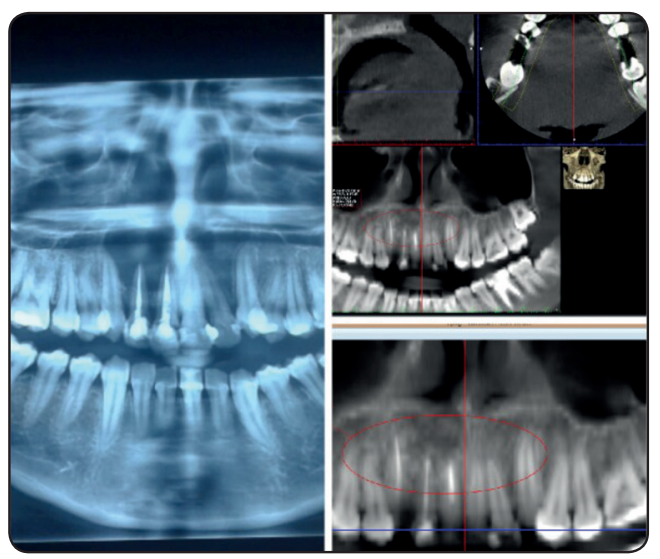

Fig. (4) Showing radiographic results of bone density measurements where is the CBCT of the other group and you didn't mention before about this figure in your writing.

\section{DISCUSSION}

Rapid advancements in maxillofacial reconstruction surgery have been applied in the last few years. Many studies supported the grafting of critical size bony defects after enucleation of odontogenic cysts. There are different types of bone grafting materials such as autografts, allografts, xenografts, and alloplasts. Many authors have concluded that the use of autogenous bone grafts and alloplastic grafts can help with healing of osseous defects by reducing the risk of possible fractures of the jaws and shorten the recovery period. ${ }^{(11)}$

All patients in this study were treated under general anesthesia. The surgical procedure included reflection of a full thickness mucoperiosteal flap with relaxing vertical incisions. This aimed to provide adequate access to the surgical field, ensure adequate enucleation and eliminate chances of possible future recurrence. This was in acceptance with Anuj et al who used the same flap. All cases in this study showed proper wound healing without presence of any clinical signs of post-operative complications in the two groups. ${ }^{(12)}$

Shankar et al had used Symbios ${ }^{\circledR}$ granules, the bone grafting material used in our study, after sinus floor elevation. They showed that these granules had statistically significant high volume fill capacity. No published articles illustrated the application of Symbios ${ }^{\circledR}$ after enucleation of large maxillary cyst. ${ }^{(13)}$

The primary outcomes in our study were pain and swelling scores that were evaluated clinically using the VAS. The results showed that the addition of PRF to the Symbios ${ }^{\circledR}$ biphasic bone graft material had no clinical effect regarding pain and swelling. This was in acceptance with Amaninder et al where is the reference ?? who had used VAS to evaluate pain and swelling between grafted and non-grafted side after bilateral mandibular impaction surgeries. They found that addition of the bone graft had no clinical significance on either pain or swelling scores. ${ }^{(14)}$

The secondary outcome in the current study was the measurement of bone density within the defect by using CBCT. The combination between the bone graft material and PRF showed statistically significantly higher mean bone density values in group (A) than group (B) with an increase of $45.03 \%$ in bone density after nine months. This result was compatible with the study of Pradel et al where is the reference?? who had demonstrated in their study that the bone density had showed an increase of $48 \%$ after one year compared to the immediate postoperative values after the complete removal of large odontogenic cysts that were left to heal spontaneously without grafting. ${ }^{(15)}$

PRF is considered one of the most promising biomaterials for its easy technique of and the wide use in different surgical applications. It has also 
been used as fragments mixed with different types of bone grafting materials to improve both bone regeneration and bone quality. ${ }^{(16,17)}$

Zhang et al evaluated the efficacy of mixing PRF in combination with FDBA to accelerate bone regeneration in a maxillary sinus lifting surgery before implant insertion. The results showed acceleration in bone regeneration rate, a reduction in maturation time of FDBA and a decrease in implant placement time (placed after 4 months rather than 8 months). This was in accordance with our study as regarding the improvement in bone regeneration and density. ${ }^{(18)}$

Yilmaz et al had compared the healing effects of $\beta$-TCP and PRF, separate and in combination with each other, in a standardized bone defects in pig's tibiae. They found that in case of mixing $\beta$-TCP and PRF together, there was a statistically significant higher difference in bone density measures of the newly regenerated bone than when used in a separate manner. Similar to the results of this study according to the bone density measurements. ${ }^{(19)}$

Also, the results of bone density measurements in our study were in acceptance with the study of Jayalakshmi et al. They used b-TCP allograft in combination with PRF for augmentation of a periapical bony defect after enucleation of a periapical cyst in the anterior part of the maxilla. There results showed that the combination of b-TCP allograft and PRF had promoted the regenerative capacity of bone. ${ }^{(20)}$

Eldibany et al had performed a study to evaluate the healing kinetics when combining Nanobone ${ }^{\circledR} *$ and PRF following enucleation of large mandibular cysts that more than $3 \mathrm{~cm}$ in any dimensions. Their study was conducted on fifteen patients. Bone density of the bony defects was evaluated using CBCT immediately post-operative, and after 6 and 9 months. In the final follow up of their study, the measurement of bone density had showed an increase of $50.8 \%$ without any clinical signs of post-operative complications. They concluded that Nanobone ${ }^{\circledR} /$ PRF combination accelerated bone healing and improved the quality and quantity of regenerated bone. ${ }^{(21)}$

The results of our study in the measurement of bone density within the defect in group (A) were similar to the results of Eldibany et al, as the combination between BGM and PRF had showed an increase of $45.03 \%$ in bone density measurement in group (A). However the difference between the Nanobone ${ }^{\circledR}$ and the Symbios ${ }^{\circledR}$ (BGM) that is the bone graft material of our concern. As the Nanobone ${ }^{\circledR}$ is a xenograft is a pure HA, while the Symbios ${ }^{\circledR}$ has only $20 \%$ of its chemical structure $\mathrm{HA}$ and the other $80 \%$ is $\mathrm{B}$-TCP. Presence of $80 \%$ of $B$-TCP in the chemical composition of BGM explains the rapid rate of resorption than pure hydroxyapatite.

However, Eldibany et al evaluated the effect of this combination on large mandibular cysts, while our study was concerned with large maxillary cysts. Regarding, the difference in bone structure between both jaws, as the maxillary bone is cancellous while mandibular bone is cortical. Also the bone density differs between the mandible and the maxilla, as the mandible is denser than the maxilla. The maxillary bone has also an increased blood supply and an excellent drainage. That is why this combination between PRF and BGM was of great effect on the maxillary bony defects. ${ }^{(22)}$.

In contrast to the results of the present study, Perjuci et al concluded that spontaneous bone healing after enucleation of large cysts should be the treatment of choice even in large cystic cavities where the residual bone defect was walled with sufficient amount of bone with uncomplicated surgical treatment modality, low financial and biological costs unlike the results of the recent study. ${ }^{(23)}$ 


\section{CONCLUSION}

On the basis of the results obtained from this study, we concluded that the combined use of Symbios ${ }^{\circledR}$ biphasic bone graft material and PRF for bone regeneration following the enucleation of large maxillary cysts induced accelerated bone healing and improved the bone density of the regenerated bone with an increase of $45.03 \%$ at the end of the follow up (9 months). However, the addition of PRF to the Symbios ${ }^{\circledR}$ biphasic bone graft material had no effect on the clinical results (pain and swelling).

To obtain optimal tissue regeneration, the defect should be covered by a membrane to preserve the grafting material, so it is recommended to use a membrane.

\section{Financial disclosure}

Our research project was not sponsored, and it did not receive any financial assistance. There was no conflict of interests.

\section{REFERENCES}

1. Martin L, Speight PM. Odontogenic cysts. Diagnostic Histopathol.2015; 21(9):359-369.

2. Slootweg PJ, Slootweg PJ. Odontogenic Cysts. Dental Pathology. 2013; 83(1) 99-117.

3. Johnson NR, Gannon OM, Savage NW, Batstone MD. Frequency of odontogenic cysts and tumors: a systematic review. J Investig Clin Dent. 2014; 5(1):9-14.

4. Bds MS, Dent D, Bds PS, Glasg F, Eng F. Cysts of the Oral and Maxillofacial Regions. 2007; 978(4):4051-4937

5. Castermans A, Vrebos J. The treatment of large odontogenic cysts. Plast Reconstr Surg. 1969; 43(4):437.

6. Keiser GJ. Odontogenic cysts and tumors of the maxilla: Controversies in surgical management. Operative Techniques Otolaryngology-Head Neck Surg.1999; 10(2):140-147.

7. Yaman Z, Suer BT. Clinical comparison of ultrasonic surgery and conventional surgical techniques for enucleating jaw cysts. Int J Oral Maxillofac Surg. 2013; 42(11):1462-1468.
8. Saluja H, Dehane V, Mahindra U. Platelet-Rich fibrin: A second generation platelet concentrate and a new friend of oral and maxillofacial surgeons. Annals Maxillofac Surg. 2011; 1(1):53.

9. Choukroun J, Diss A, Simonpieri A, Girard MO, Schoeffler C, Dohan SL, Dohan AJ MJ and DD. Platelet-rich fibrin (PRF): a second-generation platelet concentrate. Part V: histologic evaluations of PRF effects on bone allograft maturation in sinus lift. Oral Surg Oral Med Oral Pathol Oral Radiol Endod. 2006; 101(3): 299-303.

10. Ghosh R,Gopalkrishnan K. Facial fractures. Journal Craniofac Surg. 2018; 29(4):334-34.

11. Kao ST, Scott DD. A Review of Bone Substitutes. Oral and Maxillofac Surg Clinics of North America. 2007; 19(4):513-21.

12. Kumar N, Anuj S, Pramod R. Unusually Large Radicular Cysts of Maxilla: Steps in Diagnosis and Review OF Management. Journal of Bio Innovation. 2015:41(1): 645-651

13. Mehrotra G, Iyer S, Verma M. Treatment Planning the Implant Patient. International Journal Clin Implant Dent. 2010; 36(11):827-34.

14. Singh A, Kaur S, Jani M, Soni P,Thakkar P, Gupta S. The Difference in Pain and Swelling Experienced by the Patient Undergoing Bilateral Mandibular Impaction Surgery: Difference Between Grafted and Non Grafted Side. Int J Dent Med Res 2014;1(3):46-50.

15. Pradel W, Eckelt U, Lauer G. Bone regeneration after enucleation of mandibular cysts: comparing autogenous grafts from tissue-engineered bone and iliac bone. Oral Surg Oral Med Oral Pathol Oral Radiol Endod. 2006; 101(3):285-90.

16. Saluja H, Dehane V, Mahindra U. Platelet-Rich fibrin: A second generation platelet concentrate and a new friend of oral and maxillofacial surgeons. Annal Maxillofac Surg. 2011; 1(1):53-7.

17. Gupta V, Bains VK, Singh GP, Mathur A BR. Regenerative Potential of Platelet Rich Fibrin In Dentistry: Literature Review. Asian Journal Oral Heal Allied Sci. 2011; 8(5): 7922-7929.

18. Zhang Y, Tangl S, Huber CD, Lin Y, Qiu L, RauschFan X. Effects of Choukroun's platelet-rich fibrin on bone regeneration in combination with deproteinized bovine bone mineral in maxillary sinus augmentation: 
A histological and histomorphometric study. Journal Cranio-Maxillofac Surg. 2012; 24(7):607-24.

19. Yilmaz D, Dogan N, Ozkan A, Sencimen M OB and MI Effect of platelet rich fibrin and beta tricalcium phosphate on bone healing. A histological study in pigs. Acta Cir Bras 2014; 29(1) 59-65.

20. Jayalakshmi KB, Agarwal S, Singh MP, Vishwanath BT, Krishna A,Agrawal R. Platelet-rich fibrin with b-tricalcium phosphate-a noval approach for bone augmentation in chronic periapical lesion: a case report. Case Rep Dent. 2012; 2012:902858
21. Eldibany RM, Shokry MM. The effect of Nanobone ${ }^{\circledR}$ in combination with platelet rich fibrin on bone regeneration following enucleation of large mandibular cysts. Tanta Dental Journal. 2014; 100(11):108.

22. Varinauskas V, Gervickas A, Kavoliūniene O. Analysis of odontogenic cysts of the jaws. Medicina (Kaunas). 2006; 42(3): 201.

23. Ferial P, Ali G, Zana A.Evaluation of spontaneous bone healing after enucleation of large residual cyst in maxilla without graft material utilization.case report.Acta Stomatologica Croatica. 2018; 52(1):53-60. 